\section{4 \\ LA-6939-MS}

Informal Report
UC.38

Issued: September 1977

\title{
Conceptual Design of a Heat Pipe Radiator
}

\author{
Gloria A. Bennett
}

\section{scientific laboratory}

of the University of California

los alamos. NeW mexico 87545

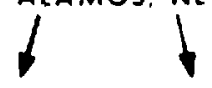

An Affirmotive Action / Equal Opportunity. Employer 
This work was supported by the US Energy Research and Development Administration, Division of Nuclear Research and Applications.

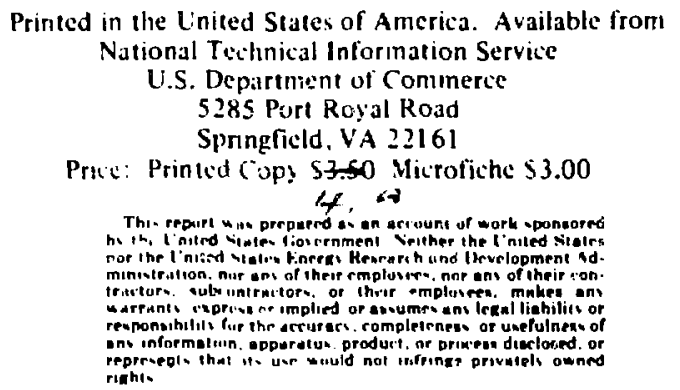




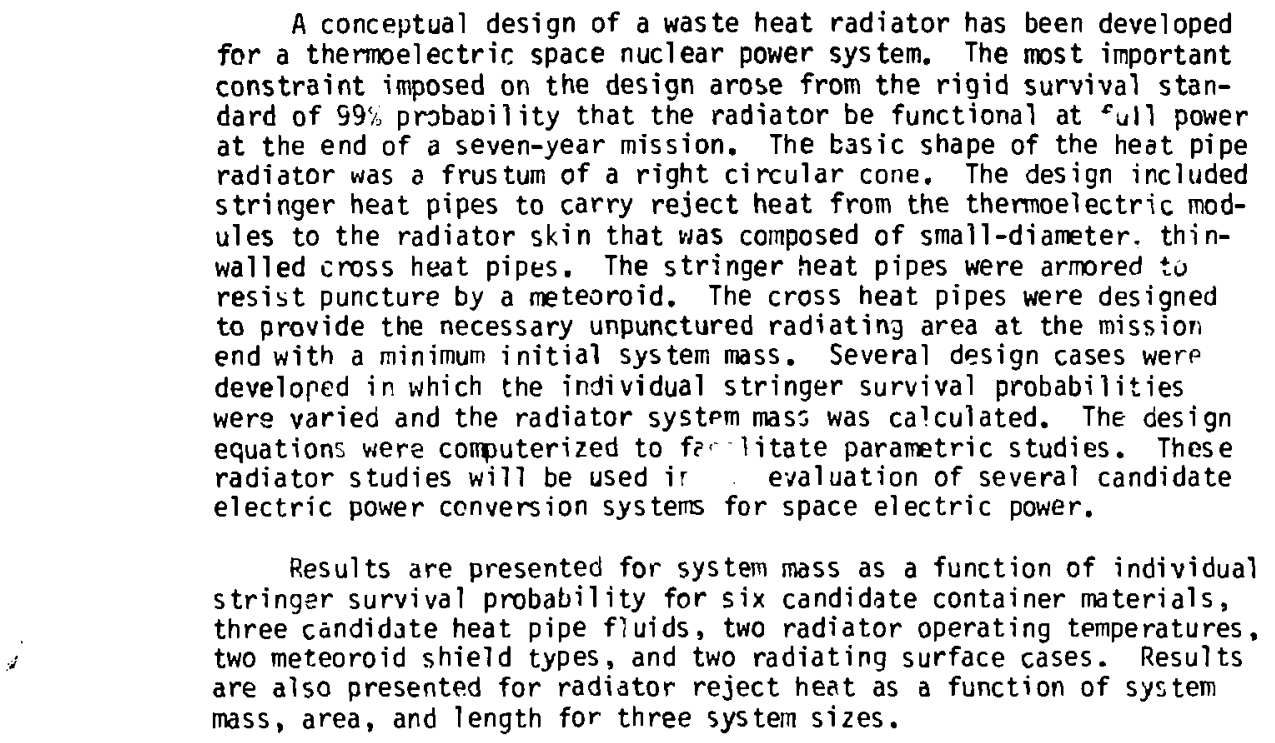

A conceptual design of a waste heat radiator has been developed for a themoelectric space nuclear power system. The most important constraint imposed on the design arose from the rigid survival standard of $99 \%$ probability that the radiator be functional at 411 power at the end of a seven-year mission. The basic shape of the heat pipe radiator was a frustum of a right circular cone. The design included stringer heat pipes to carry reject heat from the themoeiectric modules to the radiator skin that was composed of small-diameter. thinwalled cross heat pipes. The stringer heat pipes were armored tu resist puncture by a meteoroid. The cross heat pipes were designed to provide the necessary unpunctured radiating area at the mission end with a minimum initial system mass. Several design cases werp develored in which the individual stringer survival probabilities were varied and the radiator system mas; was calculated. The design equations were computerized to fa-litate parametric studies. These radiator studies will be used $i$. evaluation of several candidate electric power conversion systems for space electric power.

Results are presented for system mass as a function of individual stringer survival probability for six candidate container materials, three candidate heat pipe fiuids, two radiator operating temperatures, mass, area, and length for three system sizes.

\section{INTRODIJCTION}

The Lus Alamos Scientifi: Laboratiory (LASL), in support of the Energy Research and Development Administration (ERDA) Nuclear Research and Applications Division program to develop a nuclear space reactor power plant, is conduccing studies on mission requirements and power plant technology. The purpose of the LASL study is to determine the chararteristics of various reactor power plants for space applications and to select a configuration for future ground deronstration and fligint. Department of Defense (DOD) requirements for a power plant will strongly influence the selection of future space reactors. Currently, various fuels, reactor designe, shields, converters, and radiators are being considered. The study effort is concentrated on a high-temperature, compact, fast reactor that can be coupled with any one of several electrical power conversion systemis (thermoelectric, thermionic, or dynamic) and with various radiation shielding systems as dictated by the specific mission requirements.

A space electrical reactor power plant may be thought of as four major subassemblies: a nuclear reactor heat source; a radiation shield used to protect other spacecraft parts from hi th $^{\text {t }}$ radiation levels; a converter to transfer thermal energy to electrical energy; and a radiator to reject waste heat. This particular study was undertaken to produce a conceptual design of a waste heat radiator for a themoelectric ( $T / E)$ power system.

This repurr was propared al an ascouns of work sponkured by the Umited Stales Cimvernment Nether

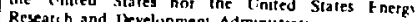

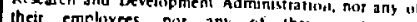
subcontractors. nor art of thetr conlfactors warraniy expics or their employees, trakes ans

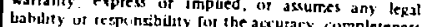


A heat-pipe-cooled system was chosen for study because it was believed to be lighter and more reliable than a conventional pumped-fluid system. The study objectives were to provide size and weight estimates for use in power plant parametric studies, to clarify potential problems, and to evaluate technical feasibility of the heat pipe concept.

The radiator was required to have a $99 \%$ probability of functioning at full design heat load at ti.e end of a seven-year mission. The only failure mechanism considered was micrometeoroid puncture of heat pipes. The overall reliability is provided by selecting sufficiently thick heat pipe material to provide a selected probability that a prescribed number of heat pipes would survive the mission. Results from previous stidies ${ }^{1}$ on radiator segmenting were used in optimizing between material thickness and redundant heat pipes to minimize the initial system mass.

\section{RADIATOR DESIGN}

The radiator configuration chosen for study was the frustum of a right circular cone. The design included $91 \mathrm{~T} / \mathrm{E}$ modules arranged in a $1.18-\mathrm{m}-$ diam circle at the small base of the frustum. The radiator was designed to use two systems of heat pipes in series, ratiler than the conventional pumped-fluid system. Ninety-one axial stringer heat pipes, arranged on the cone slant. surface, uniformly transfer heat from the T/E modules to the radiator skin. The radiating surface is cumposed of many small-diamecer, thin-walled heat pipes laid side by side at right angles to the stringers around the radiatur circumference. Heat is conducted from the stringers to cross heat pipes and then radiated to space. The design is shown in Fig. 1. The cross heat pipes are assumed to be brazed to the stringer heat pipes to provide the stringer-tocross-heat-pipe heat transfer. They may a1so be brazed to each other, but thai has no: : sen assumed in the thermal analysis.

\section{SYSTEM RELIABILITY}

The heat rejection system is composed of the cross and stringer heat pipe systems. The radiaior must have a $99 \%$ survival probability that both systems will remain functional for a seven-year mission. Functional is defined as capabie of rejecting the design heat load at the design temperature. The probability of failure from means other than meteoroid penetration is not consifered here, but must be reduced to a very small value. Because the heat pipe systems are statistically independent, the total system survival probability is given by ${ }^{2}$

$$
p(S \cap C)=p(S) \times p(C),
$$

where

$$
\begin{aligned}
p(S)= & \text { probability of stringer system surviral; } \\
& \text { and } \\
p(C)= & \text { probability of cross heat pipe sys tem } \\
& \text { survivil. }
\end{aligned}
$$

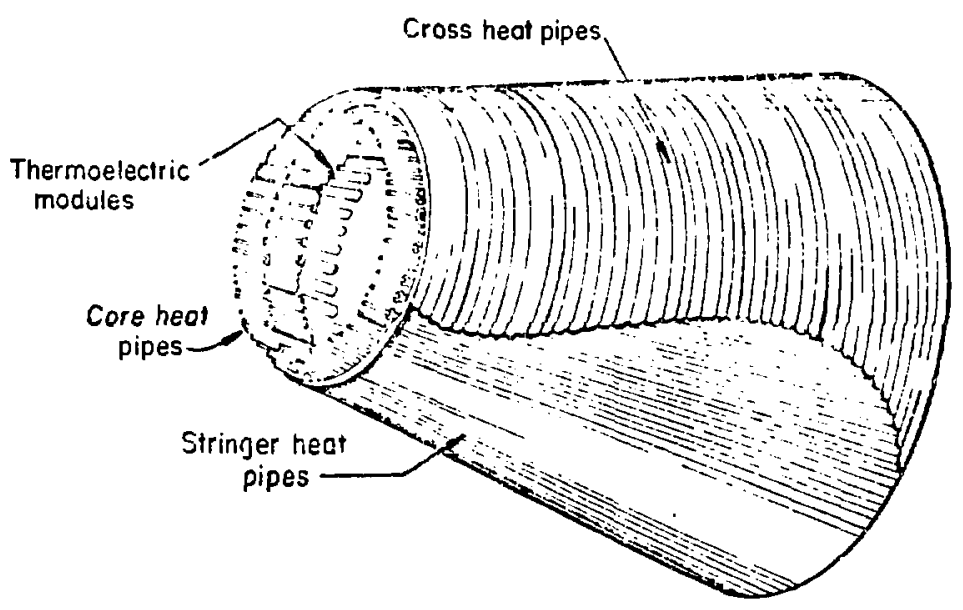

5ig. 1. Ninety-one heat pipe thermoelectric system radiator. 
The systems survival probability is equal to 0.99 , which is the product of 0.995 and 0.995 . Thus, the survival probability of each system must be at

least $99.5 \%$.

Twc failure modes from hypervelocity impact were considered. A dimple failure mode is assumed for the stringers and a perforation failure mode is assumed for the cross heat pipes. The difference in beryllium wall thickness as a function of individual survival probability for a vulnerable area of $0.1 \mathrm{~m}^{2}$ is shown in Fig. 2 for both failure modes.

The reference design of the 91 -heat pipe T/E system radiator assumes a $200-\mathrm{kW}$ reactor, $5 \%$ effi. cient silicon-germanium $T / E$ modules, and a radiator cperating temperature of $775 \mathrm{~K}$. The stringer and cross heat pipe container material is assumed to be beryllium and the working fluid is potassium.

\section{A. Stringer Heat Pipe System}

The stringer heat pipe system was composed $0^{\text {f }}$ 91 heat pipes. The evaporator section of earh pipe is thermally linked to the cold junction of a single T/E module. The el parator section design is not covered in this report. The assumption is made that there will be thermal coupling between $T / E$ module. so that failure of a stringer reat $p$ ipe does not result in failure to cool a T/F. module.

In this study, it was necessary to develup several design cases based on different stringer probabilities. The systeril mass determined for each survival probability was used to choose a reference design case. Because the condenser sections of each stringer heat pipe are statistically independent of all the other stringers, the system survival probability can be calcuiated using the cumulative binomial distribution?

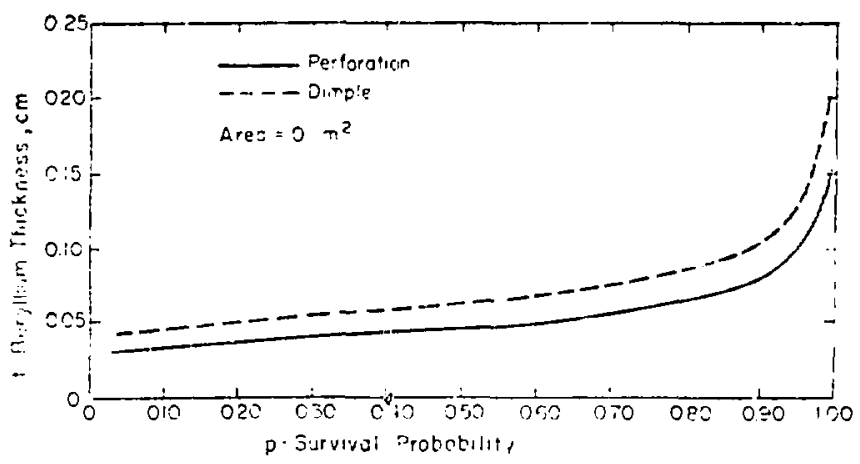

Fig. 2. Berylliuln thickness for performance and dimple failuse modes.

$$
S=\sum_{n=N}^{N} \frac{N !}{(N-n) ! n !}(1-p)^{N-n} p^{n}
$$

where

$p=$ individual stringer survival probability;

$N=$ total number of segments;

$N_{S}=$ number of surviving segments; and

$S=$ probability that $N_{s}$ segments are not punctured during the mission.

Figure 3 illustrates the calculated system survival probability as a function of the number of surviving stringers, $\mathrm{N}_{s}$, for four survival probabilities. The calculations show, for example, that of 91 heat pipes, each having a 0.89 survival probability, there is a $99.5 \%$ probability that 73 will survive.

These calculations are used to determine the end-of-life nlinber of stringers from which the resulting heat lcad per stringer car be determined. The end-of-life heat load per stringer is

$$
q_{\max }=Q_{r e j} / N_{s},
$$

where $Q_{\text {rej }}=$ total heat to be rejected, and this was used to size the stringer. The cross sectional area of the heat pipe was calculated using the sonic

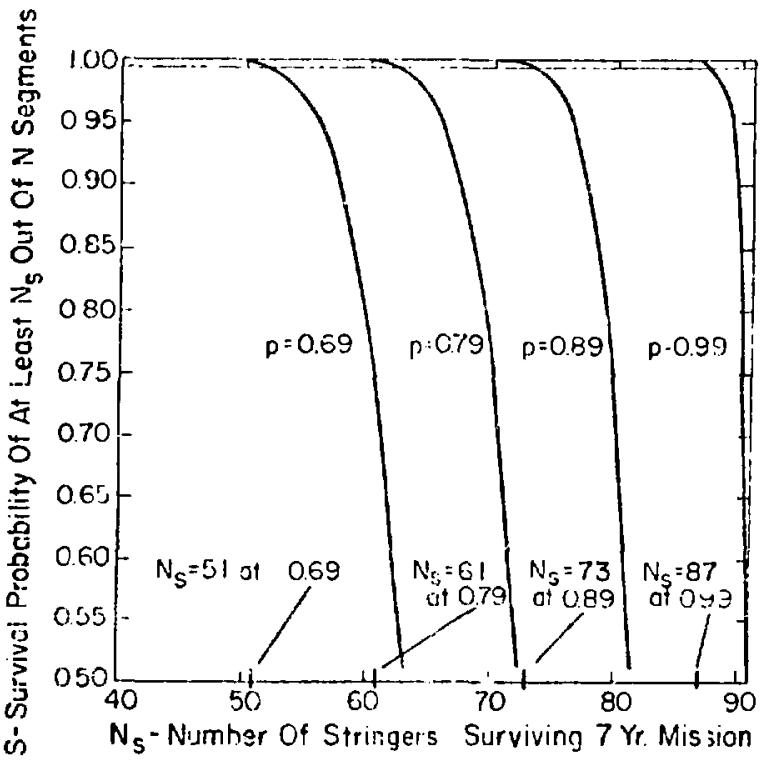

Fig. 3. System survival probability versus number of surviving stringers. 
limit of the heat pipe fluid at the operating temperature, ${ }^{3}$ multiplied by a safety factor of 2 .

The minimum length of the cundenser section is assumed to oe the slant height of the conical radiator. Pressure drop calculations for the given stringer lengths were done by J. [. Kemme ${ }^{4}$ and show favorable pressure and temperaturo profiles. B. Cross Heat Pipe System

The cross heat pipe systenl was composad of many thin-walled heat pipe segments that operated independently. The cross heat pipes were assuind to be the only surfaces that radiated waste heat to space and were the most vuinerable radiator parts. If the cross heat pipes were circumferentially segmented, then only the punctured segmients would be sacrificed as useful radiating surface.

.n Ref. 1 , $i_{2}$, as shown that the mass-per-unit area required decreased with increasing numbers of segments; for many segments and minimum initial mass, the individual segment survival probability tends toward

$$
p=\left(N_{5} / N\right)_{\min }=0.78
$$

Figure 4 illus "mates the heat pipe thickness required as a functi :. of segment survival probability for five exposed vulnerable areas. Thickness begins to increase rapidly for survival probabilities greater than about 0.85 . The exposed area causes significant increases in thickness, which

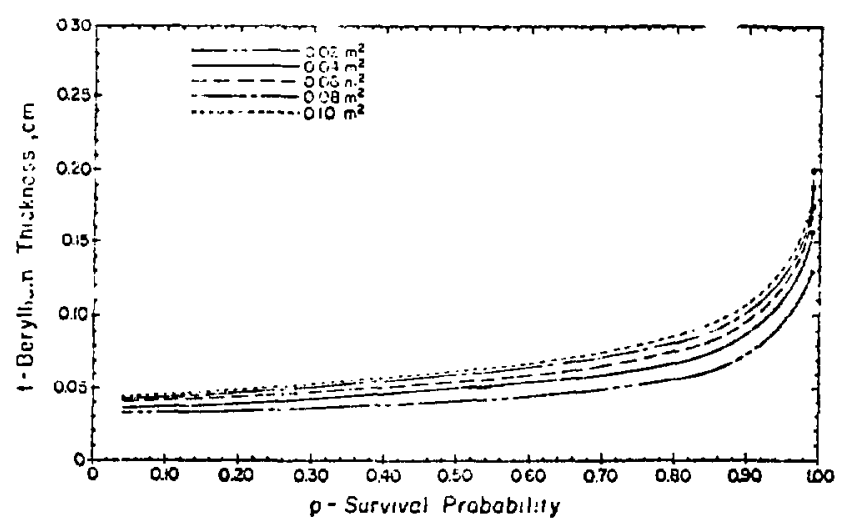

Fig. 4. Beryllium thickness vs survival piabability. means that a weight savings can be achieved by dividing a heat pipe into shorter sections. Segmenting is feasible with crrss heat pipes, but is not necessarily feasible with the stringers.

For the reference design radiator, the cross heat pipes are segmented into approximately 3200 segments on the radiator surface. Using the cumulative binomial distribution, Eq. (2), the required individual segment survival probability can be calculated so that there is a 0.995 probability of 0.78 fraction of the cross heat pipes surviving the mission. Then, using the individual survival probability and the exposed vulnerable area of each segment, the required thickness of the cross heat pipes can be calculated. The cross heat pipes outside the stringers act as a meteoroid shield or bumper, and inust be considered when calculating the wall thickness of the stringers. The bumper effect of the cruss heat pipes was estimated by the methods described in Ref. 5 .

IV. THERMAL DESIGN

The thermal environment assumed for the radiator 6 is as follows:

Solar radiation

Earth radiation ก०. $76 \mathrm{~W} / \mathrm{m}^{2}$

Space sink temperature $243 \mathrm{~W} / \mathrm{m}^{2}$

o $K$

The heat balance consists of inputs of direct solar radiation, earth-emitied radiation, reflection of solar radiation from the earth, and the internally generated heat load to be rejected, all of which must be radiated to space. The controlling equation is given by

$$
\begin{aligned}
& a_{s} \bar{F}_{s} G_{s}+a_{r} \bar{F}_{r} \bar{A}_{p} G_{s}+a_{e} \bar{F}_{e} E_{e}+\bar{P}_{i} \\
& =\sigma e \bar{T}^{4}(\operatorname{Ref} .7),
\end{aligned}
$$

where

$$
\begin{aligned}
& a_{s}= \text { solar absorptivity }=0.21 ; \\
& \bar{F}_{s}= \text { cosine of angle between the unit surface } \\
& \text { normal vector and the direction to the } \\
&\text { sun }(0 . \cdots) \text {; }) \\
& G_{5}= \text { solar irradiation on a plane normal to } \\
& \text {. the sun }=1398.76 \mathrm{~W} / \mathrm{m}^{2} ; \\
& a_{r}= \text { alsorptivity to radiation reflected from } \\
& \text { planet }=0.21 ;
\end{aligned}
$$




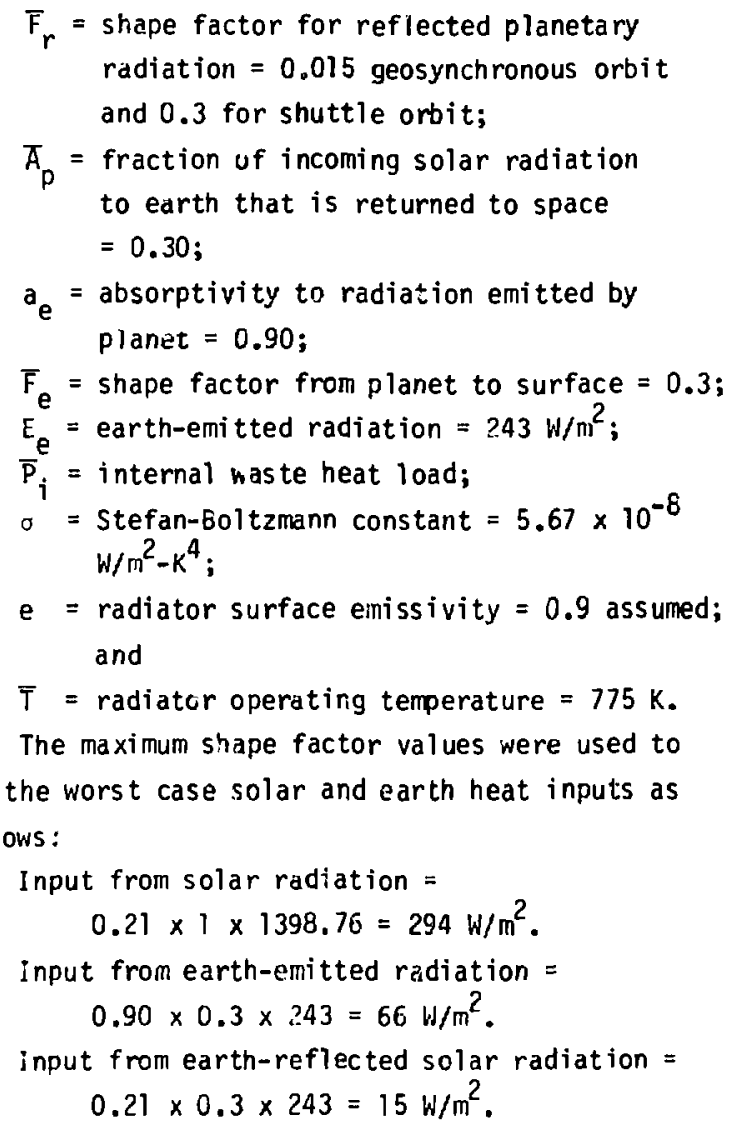

It was assumed that tio bise lonks directly at the payload so that earth-emitied and earth-ref.ected radiation would be shielded from the radiator; therefore, the total envirormental input is $294 \mathrm{~kJ}$ ?

The average radiator temperature is assumed to be constant and equal to the cross neat pipe temperature. The radiator temperature for the reference $T / E$ design case is $775 \mathrm{~K}$, at which temperature the heat rejected per unit area is:

$\frac{\text { Solar input }}{\text { Projected area }}+\frac{\text { Waste heat load }}{\text { Effective area }}$

$=\frac{\text { Heat radiated to space }}{\bar{E}}$,

$294 \mathrm{~W} / \mathrm{m}^{2}+\frac{\overline{\mathrm{P}}_{i}}{\mathrm{~A}_{\mathrm{eff} \mathrm{m}^{2}}}=5.67 \times 10^{-8}$

$\times 0.9 \times(775 \mathrm{k})^{4} \mathrm{~W} / \mathrm{m}^{2}$.

The solar input is very small compared to the heat rejectef, so that only small errors result from using the worst case solar input values applied to the effective radiator area. The resultant safety factor, SF, applied to solar input is given by

$$
\begin{aligned}
S F & :=\frac{\text { Effective radiator ared }}{\text { Projected radiator area }} \\
& =\frac{\pi\left(R_{1}+R_{2}\right) S}{\left(R_{1}+R_{2}\right) S \times \cos \phi},
\end{aligned}
$$

where

$$
\begin{aligned}
& R_{1}=\text { cone small radius; } \\
& R_{2}=\text { cone large radius; } \\
& s=\text { cone slant height; and } \\
& \phi=\text { cone half angle. }
\end{aligned}
$$

The effective area required to reject the total heat load at the design temperature is given by

$$
A_{e f f}=\bar{P}_{i} /\left(\sigma \text { e } T^{4}-I\right)
$$

where

$$
I=\text { solar input }=294 \mathrm{~W} / \mathrm{m}^{2} .
$$

The effective area represents the radiating area available and functioning at the end of the mission (EOM). The radiating area at the beginning of the mission (BOM) must be larger to compensate for loss of cross heat pipes, as was discussed in the section on reliability.

The radiator is assumed to be a frustum of a right circular cone, Fig. 5. The overall radiator siz's must be ccimpaitible with available launch vehicies such as Titan III or the Space Shuttle, whose diameters are approximately $4.2 \mathrm{~m}$. The effective radiator area is assumed to be the outer slant surface of the cone, plus, in some cases, che eraction of area visible through the cone base. The slant surface area is

$$
A=-\left(R_{1}+R_{2}\right) \times:(\operatorname{Ref}, 8):
$$

where

$$
\begin{aligned}
A= & \text { area of slant surface; } \\
s= & \text { slant height of cone; } \\
R_{1}= & \text { small radius }=0.59 \mathrm{~m} \text { in reference design; } \\
R_{2}= & \text { Jarge radius; } \\
4= & \text { half angle of cone }=12^{\circ} \text { in reference } \\
& \text { design. }
\end{aligned}
$$

Cases that a? ?ow radiation to shine through the base of the cone result in 


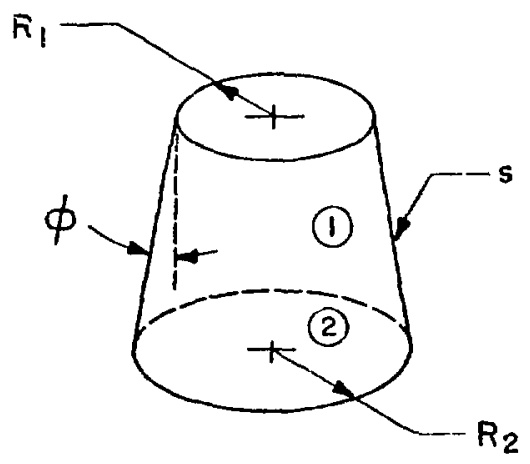

Fig. 5. Lone frustum.

$$
A_{\text {eff }}=A+F_{1-2} \times A=A\left(1+F_{1-2}\right) \text {. }
$$

where

$F_{1-2}=$ shape factor.

In both cases, the cone slant height is calculated in terms of $R_{1}, \phi, A_{\text {eff }}$ as

$$
\begin{aligned}
S & =\left(-2 \pi R_{1}+\left[\left(2 \times \pi \times R_{1}\right)^{2}\right.\right. \\
& \left.\left.-4 \times \pi \sin \phi \times A_{e f f}\right]^{1 / 2}\right) /(2 \times \pi \times \sin \phi) .
\end{aligned}
$$

Whether or not credit can be taken for base shine through is mission- and payload-dependent and will require consideration of the particular case. The expectation is that the void space inside the radiator will have instrumentation, controls, or equipment that must be protected from the high-temperature radiator. Consequently, it was assumed for the reference design that the backside of the radiator base would be looking directly at the payload that may need protection. Not taking credit for bas" shine through results in a larger and heavier radiator.

\section{v. MICROMETEOROID CRITERIA}

The radiator must be designed to minimize failure because of dainge from micrometeoroids. The only radiator parts that require thick walls are the stringer heat pipes from the $T / E$ converters to the cross heat pipes on the cone surface. The dimple failure mode was assumed for the stringers, and perforation failures were assumed for the cross heat pipas. The cross heat pinas were assumed to be significantly segmented to avoid the necessity for thick armor. The meteoroid model used for these calculations is given in Ref. 6. It includes comet particles having masses betwein 1 and $10^{-12} \mathrm{~g}$ for sporadi: meteoroids and 1 to $10^{-6} \mathrm{~g}$ for $\mathrm{stream}$ meteoroids. The average total environment is

$\begin{array}{ll}\text { Particle density } & 0.5 \mathrm{~g} / \mathrm{cm}^{3} \\ \text { Particle velocity } & 20 \mathrm{~km} / \mathrm{s}\end{array}$

Flux mass models:

$$
\text { For } \begin{aligned}
& 10^{-6} \leqslant M \leqslant 1 \text { fog } N t=-14.37-1.213 \log M . \\
& \text { For } 10^{-12} \leqslant M \leqslant 10^{-6}, \\
& \log N t=-14.339-1.584 \log M \\
&-0.063(\log M)^{2} .
\end{aligned}
$$

$N t=$ number of particles $/ m^{2} / s$ of mass $M$ or greater, and $M=$ mass in grams.

The equation used to determine the material thickness required for protection of vulnerable radiator parts from micrometeoroid impact was developed by Haller and Lieblein as: 5

$$
\begin{aligned}
& \delta=Y_{R} a\left(\frac{\rho_{p}}{\rho_{a}}\right)^{1 / 2}\left(\frac{V_{p}}{C_{a}}\right)^{2 / 3}\left(\frac{6}{\pi_{p}}\right)^{1 / 3}\left(\frac{E a A_{v} t}{-\ln P_{o}}\right)^{1 / 3 B} \\
& \left(\frac{2}{3 n \theta \rho+2}\right)^{1 / 3 B}\left(\frac{T}{T_{R}}\right)^{1 / 6}=
\end{aligned}
$$

where

$\delta$ = armor thickness, $\mathrm{cm}$;

$Y_{R}=$ room temperature cratering coefficient;

$a=$ rear surface damage thickness factor;

$b_{p}=$ meteoroid average density, $0.5 \mathrm{~g} / \mathrm{cm}^{3}$;

$\rho_{a}=$ arror density, $\mathrm{g} / \mathrm{cm}^{3}$;

$V_{p}=$ meteoroid average velocity, $20 \mathrm{~km} / \mathrm{s}$;

$c_{a}=$ sonic velocity in armor, $\mathrm{km} / \mathrm{s}$;

$E=$ armor earth shielding factor $=0.993$ for geosynchronous orbit;

$\alpha=$ meteoroid flux constant $\left(10^{-14.37} \mathrm{~g}^{\beta} / \mathrm{m}^{2}-\mathrm{s}\right.$ $=4.2658 E-15 g^{6} / m^{2}-5$;

$A_{v}=$ vulnerable araa, $m^{2}$;

$t=$ mission time, $s=7$ yrs $=2.20752 \mathrm{E}+8 \mathrm{~s}$;

$P_{0}=$ design probability of no critical damage, $p=0.69 * 0.99$;

$n$ = damage factur for oblique impact, 1.0;

$\theta=$ penetration cons tant, 0.667 ;

$8=$ meteoroid flux constant, 1.213; 
$T$ = armor temperature, $K$; and

$T_{R}=$ room temperature, $K$.

The earth shielding factor depends on orbit altitude and is defined as the ratio of shielded to unshielded flux. Figure 6 illustrates the geometry for $c$ ? culating the earth shielding factor, $E$.

$$
E=\frac{1+\cos \theta}{2} \quad(\operatorname{Ref} .5)
$$

The data on cratering coefficients came from Refs. 9, 10, and 11. The data on rear surface damage thickness factors came from Refs, 11 and 12 . The remaining material properties came from Ref. 13.

The vulnerable area is calculated based on the area of the condenser section of one stringer heat pipe as

$$
A_{v u l}=\pi \times D_{i} \times s\left(m^{2}\right)
$$

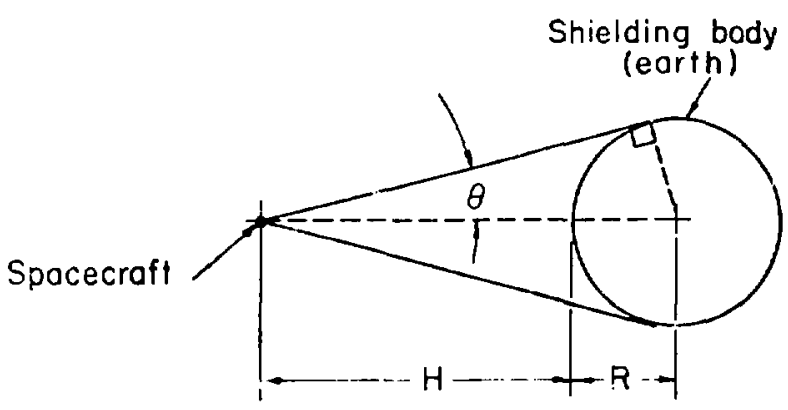

Fig. 0. Geometry for earth shielding factor.
The mission time is assumed to be seven years or $t=2.20752 \times 10^{8} \mathrm{~s}$. The design probability for critical dumage was varied in four steps from $p=0.69$ to $p=0.99$.

Six candidate radiator materials were considered. Table I 1 is ts the properties used in the calculation of required thickness. The validity of the data is difficult to judge. The beryllium data, in particular, are questionable because significant improvement has been made in the fabrication of beryllium to improve its ductility. 14

Some new materials have not been tested. The material data are used with the expectation that future testing and development of materials, if dcne, will show that these values are very conservative.

\section{RESULTS}

Results from this study fa!l into two categories. The first set of results shows the effects of cnanges in design parameters on the reference radiator system mass for four different stringer survival probabilities. The second set of results illustrates changes in the heat pipe radiator as a function of system size for the selected survival probability of $p=0.89$.

A. Effect of Design Parameters on System Mass

The reference design of the 9-heat pipe T/E sustem radiator assumes a $200-\mathrm{kW}$ reactor, 5: efficient silicon-germanium $T / E$ modules, and a radiator

TABLE I

PROPERTIES OF CANDIDATE RADIATOR MATERIALS

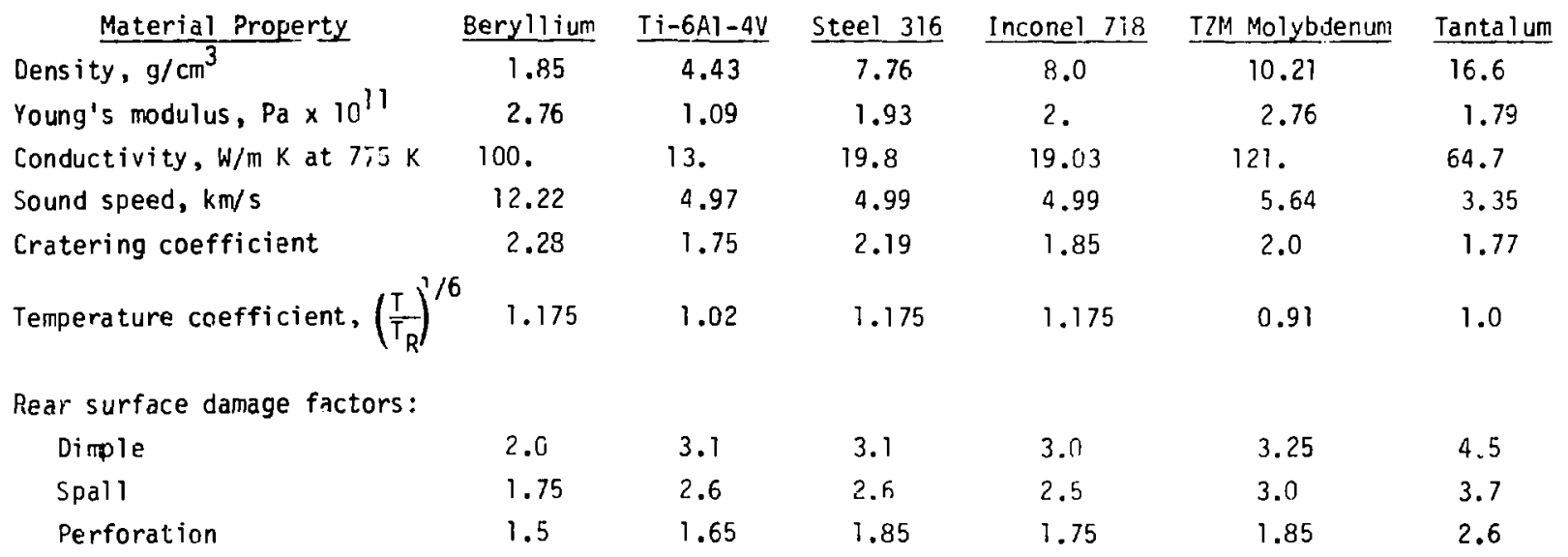


operating temperature of $775 \mathrm{~K}$. The thermal input to the radiator in a $3.22 \times 10^{7} \mathrm{~m}$ geosynchronous orbit is $294 \mathrm{~W} / \mathrm{m}^{2}$ from direct solar radiation. The reference configuration is for no shine through the radiator cone base and use of the cross heat pipes as bumpers for the stringer heat pipes. Potassium was selected as the reference heat pipe fluid and pure beryllium as the container and wicking material.

Figure 7 shows the radiator mass as a function of stringer survival probability for the reference radiator and a radiator with the calculated thickness of heat pipe container material. The reference radiator takes credit for the bumpering effect and protection that the cross heat pipes provide for the stringers by using unly $40 \%$ of the calculated materiai thickness. Neglecting to take cradit for the protection afforded by the cross heat pipes results in 43 to $73 \%$ heavier radiator mass.

Figure 8 illustrates the radiator mass for the six candidate coniainer materials considered. The materials were selected for their usefulness at el evated temperatures over long periods and for

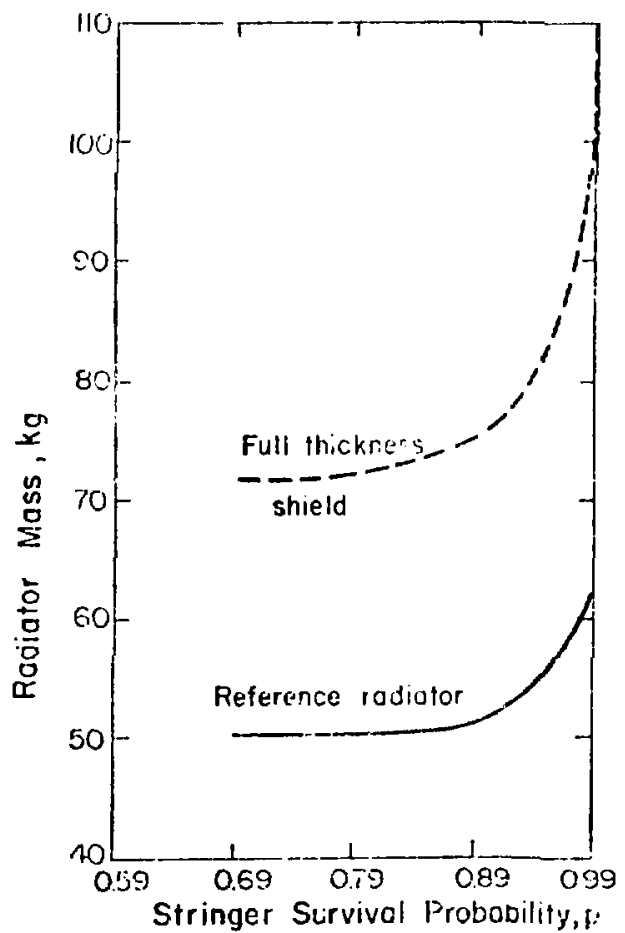

Fig. 7. Radiator mass with and without bumper iffect.

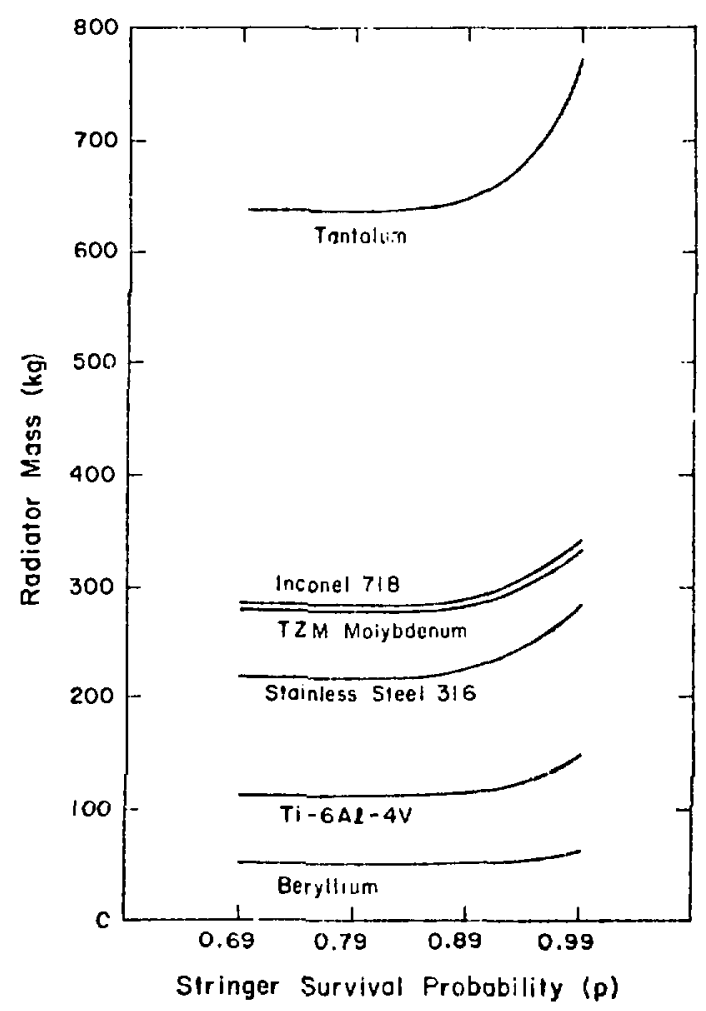

Fig. 8. Radiator mass for six candidate container materials.

the availability of data from hypervelocity impact experiments. The data used for all the materials except bery $11 \mathrm{i}$ um and titanium are from Refs. 9, 10, 11 , and 2. The rear surface damage factors for beryllium and tantalum were assumed to be similar to those of titanium; the cratering coefficient for Ti-6Al-4V and the temperature coefficient for tantalum were estimated. Results show that pure beryllium yields the lightest radiator, with $T i-6 A 1-4 V$ giving the next lightest.

Figure 9 illustrates the effect of changes in heat pipe fluid on the radiator mass. The cesium and potassium curves are similar because of the similar densities and sonic limits at the operating temperature. The mass of a radiator with mercury heat pipe fluid is significantly larger, primarily because of the density of mercury. Potassium was chosen as the reference heat pipe fluid because it has a higher latent heat of vaporization and a higher liquid transport factor than cesium ${ }^{3}$ and yitlds the lightest radiators. 


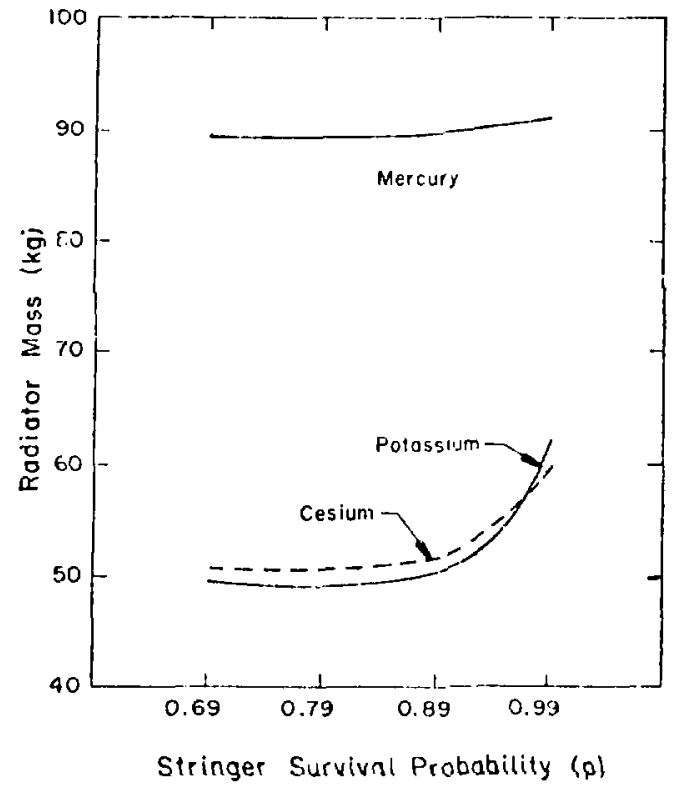

Fig. 9. Radiator mass for three candidate heat pipe fluids.

Figure 10 shows radiator mass as a function of stringer survival probability for the two assumed radiator surface configurations. Since allowance for shine through the base of the radiator cone is mission- and payload-dependent, the reference design is the conservative choice. The mass of a radiator that allows shine through the base would be approximately $87 \%$ of the reference design mass.

Figure 11 illustrates the effect of operating temperature on the radiator mass. When the operating temperature was lowered from 775 to $675 \mathrm{~K}$, allowing only a small approach temperature between the heat pipe systems, the radiator mass increased from 185 to $235 \%$ of the reference radiator mass.

With only one exception, all changes in the reference design assumptions or parameters increased the radiator system mass. The choice of a heat pipe container materiai has the most significant effect on system mass. The material properties and empirical coefficients used to determine meteoroid shield thickness at the design temperatures should be well established for the selected container material. B. Effect of System Size on Heat Pipe Radiator The reference design assiumes use of a $200-\mathrm{kW}$ reactor with $5 \%$ efficiert si7icon-germanium $T / E s$;

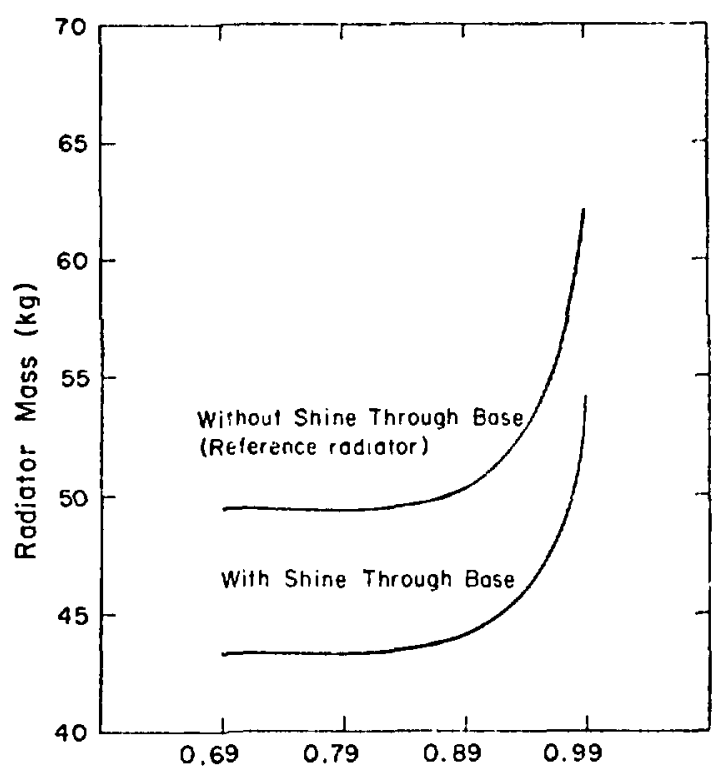

Stringer Survival Probobility $(p)$

Fig. 10. Radiator mass with and without shine through base.

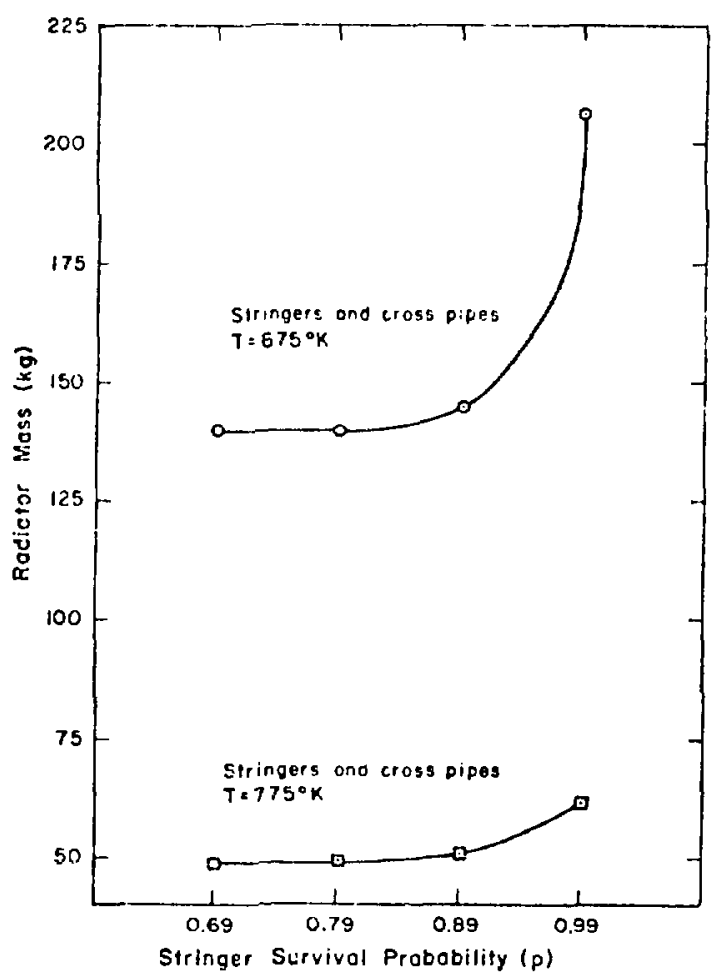

Fig. 11. Radiator mass for two operating temperatures. 
an? ar ter systems assumed a 600-kw reactor with $5 \%$ aficient silicon-germanium T/Es and a 1000-kW re5600 , with $10 \%$ afficient selenide T/E modules.

Fs fura $: \angle$ is a plot of reject heat as a function of "aciliator system mass for a stringer survival probasitity of 6.89 . Figures 13 and 14 are plots of reit: iezt as a function of radiator area and slant neight, respectively. The curves indicate that the intijicr mass, at a given stringer survival probaDilify, increases nearly linearly with reject heat. Tat: le 11 lists size and mass information for the three different systems.

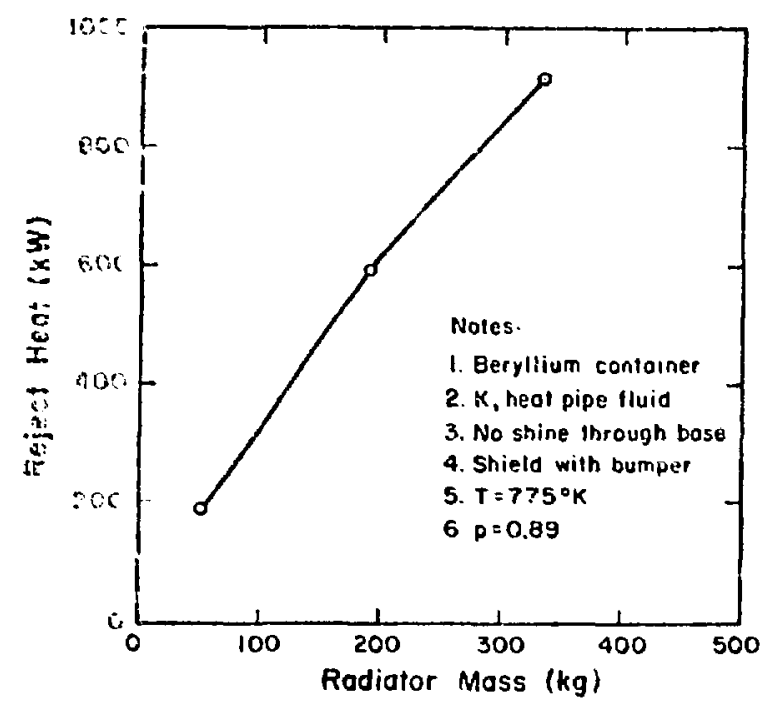

?i.. 12, Radiator mass vs reject heat.

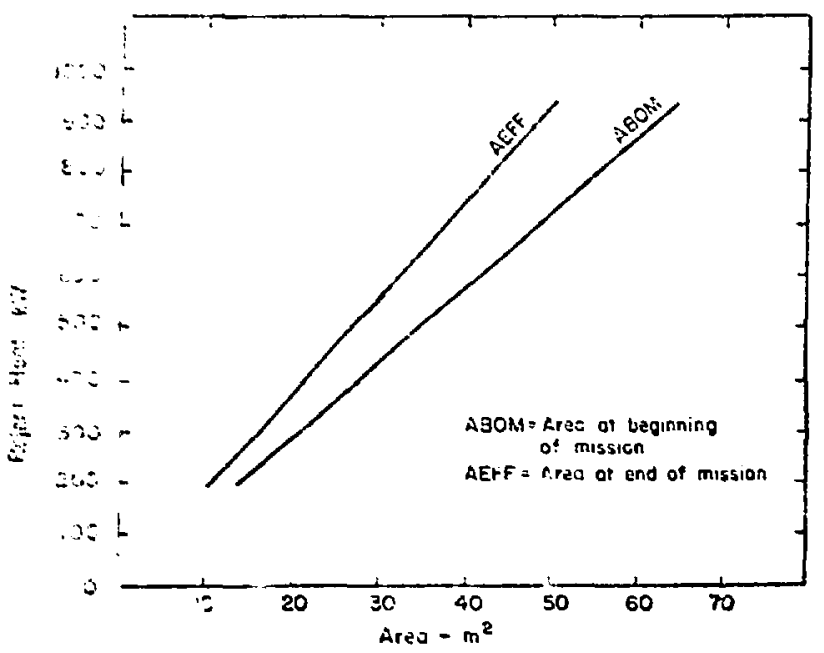

Fig. 13. Radiator area vs reject heat.

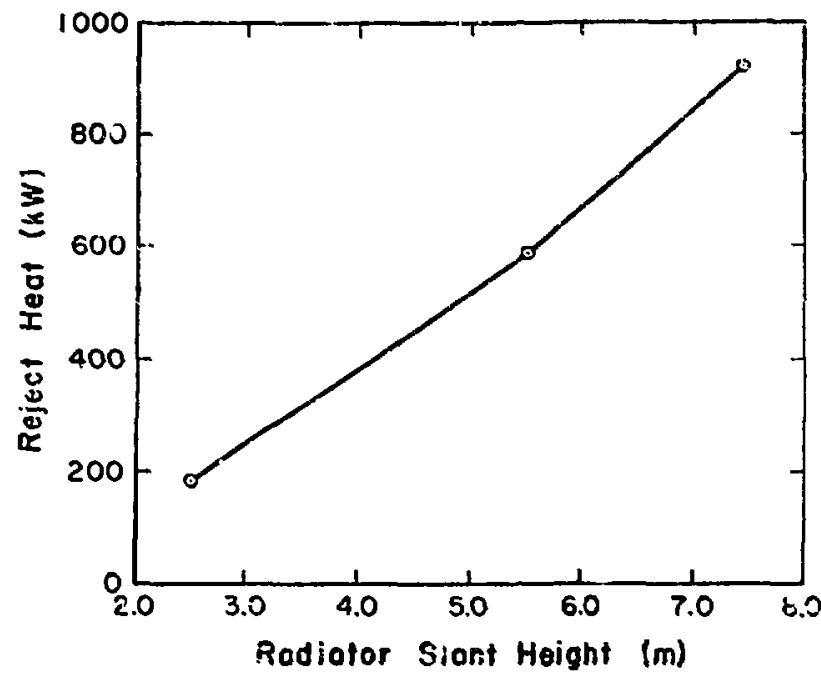

Fig. 14. Radiator slant height vs reject heat

TABLE II

RADIATOR SYSTEM SIZE AND MASS DATA

\section{Parameter}

Reactor power, $\mathrm{kW}$

Converter efficiency,

Omax/stringer, $w$

$200 \quad 600 \quad 1000$

Stringer i.d., $\mathrm{cm}$

793512529

Armor thickness, cm

$\begin{array}{lll}2.28 & 3.94 & 4.95\end{array}$

Radiator small diameter, $m$

$\begin{array}{lll}0.12 & 0.174 & 0.20\end{array}$

Radiator large diameter, $m$

$\begin{array}{lll}1.18 & 1.18 & 1.18\end{array}$

$2.23 \quad 3.47 \quad 4.27$

Radiator slant height, $m$

Radiating area at $\mathrm{BOM}, \mathrm{m}^{2}$

$2.51 \quad 5.5 \% \quad 7.44$

Number of cross heat pipes

13.45

$40.34 \quad 63.7$

$3263 \quad 7176 \quad 9672$

Specific mass, $\mathrm{kg} / \mathrm{kW}$

$\begin{array}{lll}0.263 & 0.332 & 0.369\end{array}$

Stringer heat pipe mass, $\mathrm{kg}$

$\begin{array}{rrr}15 & 82 & 160 \\ 23 & 75 & 123 \\ \frac{12}{50} & \frac{32}{189} & \frac{49}{332}\end{array}$

vii. CONCLUSIONS

The results of this study indicate that the reference design sl-heat pipe radiator is the lightest functional radiator that meets the imposed system survival criteria. ho consideration was given to fabrication difficuities involved in the production of long, thin-walled beryllium cylinders. 
1. R. F. English and D. E. Guentert, "Segmenting of Radiators for Meteorite Protection," American Rocket Society Journal 31, 1162 i164 (1961).

2. Invir Miller and John E. Freund, Probability and Statistics for Engineers, (Prentice Halt. Inc., Ennlewood Cifffs, 1965), pp. 19-32.

3. "Heat Pipe Design Handbook," National Aeronautics and Space Administration report DRD No. SE-354 T (August 1972).

4. J. E. Kenme, Los Alamos Scientific Laboratory, personal communication, 1977.

E. W. H. Dauterman and L. D. Montgomery, "Design and Analys is of the Radiator Structure for Space Power Systems," Atomics International Division Rockwell International report AI-AEC-13093 (June 22, 1973).

6. "Space Shuttle Program - Space Shuttle System Payload Accommodaticns, Level II Program Definition and Requirements. Vol. XIV," National Aeronautics and Space Administration report JSC-07700 (November 26, 1975).

7. Frank Kreith, Radiation Heat Transfer for Spacecraft and Solar Power Plant Design (International Textbook Co., Scranton, 1962), pp. 80-82.

8. CPC Standard Mathematical Tables (CRC Press, Inc., CTeveland, $9, \overline{4}$, p. 77.
9. Nestor Clough and Seymour Lieblein, "Crater Characteristics of 11 Metal Alloys Under HyperVelocity Impact Including Effects of Projectile Density and Target Temperatures," General Motors Corporation, Warren Research Laboratories report NASA-TN-D-5135 (April 1969).

10. James H. Diedrich and Irvin J. Loeffler, "Hypervelocity Impact Damage Characteristics in Beryllium and Graphite Plates and Tubes," General Motors Corporation Defense Research Laboratories report NASN-TN-D-3018 (1965).

11. Nestor Clough, J. H. Diedrich, and Seymour Lieblf:in, "Results of Hypervelocity Impacts inco space Radiator Materials," Proc. Rankine Cyrie Space Power Systems Special ists Conference, Ist, Cleveland, $\mathrm{OH}$, Cctober 26-28, 1965.

12. Nestor Clough, Seymour Lieblein, and Allen R, McMillan, "Dimple, Spa!l, and Perforation Characteristics of Thin Plates of Nine Materials Under Hypervelocity Impact," Lewis Research Center report NASA-TN-D-5625 (January 1970).

13. Taylor Lyman, Ed., Metals Handbook 8th Edition, Vol. 1, Properties and Selection of Metals (American Societv for Metals, Metals Park, OH, 1961).

14. L. B. Lundberg, Los Alamos Scientific Laboratory, personal communication, 1977. 